\title{
Recent trends and future directions for the medical treatment of ulcerative colitis
}

\author{
Makoto Naganuma $^{1} \cdot$ Shinta Mizuno $^{1} \cdot$ Kosaku Nanki $^{1} \cdot$ Shinya Sugimoto $^{1} \cdot$ \\ Takanori Kanai ${ }^{1}$
}

Received: 6 September 2016/ Accepted: 22 September 2016/Published online: 3 October 2016

(C) Japanese Society of Gastroenterology 2016

\begin{abstract}
Recently, several medical treatments for ulcerative colitis (UC) have been developed, including 5-aminosalicylic acids (5-ASAs), corticosteroids, thiopurine, calcineurin inhibitors, and anti-tumor necrosis factor (TNF) $\alpha$ treatments. Treatment options including calcineurin inhibitors and anti-TNF treatment for refractory UC are discussed in this article. Furthermore, upcoming treatments are introduced, such as golimumab, vedolizumab, AJM300, tofacitinib. Budesonide foamwill be used as one treatment option in patients with distal colitis. Herbal medicine, such as Qing-Dai is also effective for active UC and may be useful for patients who are refractory to anti$\mathrm{TNF} \alpha$ treatments. In the near future, physicians will able to use many different treatments for UC patients. However, we should not forget 5-ASA and corticosteroids as the fundamental treatments for UC patients.
\end{abstract}

Keywords Ulcerative colitis - Calcineurin inhibitors · Anti-TNF treatments - Anti-adhesion antibody .

The current treatment guideline for UC

\section{Recent trends in treatments for refractory ulcerative colitis (UC)}

Although the etiology and morbidity of ulcerative colitis (UC) were unknown and a fundamental treatment did not exist, the pathophysiology of UC has been extensively

Makoto Naganuma

nagamakoto@z7.keio.jp

1 Department of Gastroenterology, School of Medicine, Keio University, 35 Shinanomachi, Shinjuku-ku, Tokyo 160-8582, Japan studied and involves host genetic factors, immune system dysregulation, and environmental factors such as smoking, food, and microbiota [1]. To date, several medical treatments have been developed, including 5-aminosalicylic acids (5-ASAs) [2], corticosteroids [3], thiopurine [4, 5], calcineurin inhibitors [6-8], and anti-tumor necrosis factor (TNF) $\alpha$ treatments $[9,10]$. The fundamental treatments for UC include 5-ASA and corticosteroids, and these treatments should be used initially in most cases. For mild to moderate extensive UC, oral 5-ASA with/without topical 5-ASA should be used, and corticosteroids should be used in patients who are refractory to 5-ASA or have severe UC [11]. The current guidelines for UC are summarized in Fig. 1.

For the patients who are refractory to 5-ASA/corticosteroid or are steroid-dependent, alternative treatments should be used. Thiopurines have shown some efficacy for inducing remission in patients with UC; however, they should be mainly used to maintain clinical remission because thiopurines are less effective for patients with UC than for patients with Crohn's disease (CD), and there are other, more effective treatments available for inducing clinical remission [12]. For inducing clinical remission, apheresis therapy, calcineurin inhibitors, and anti-TNFa treatments are often used in Japan. Although apheresis has been reported to be effective [13-16], the results from a recent clinical trial indicated there was no significant benefit of apheresis therapy for treating patients with active UC [17].

\section{Calcineurin inhibitors}

For calcineurin inhibitors, there are two types of treatments [cyclosporine (CsA) and tacrolimus (Tac)] that have been used in UC patients. Although the pharmacological 
Inducing clinical remission

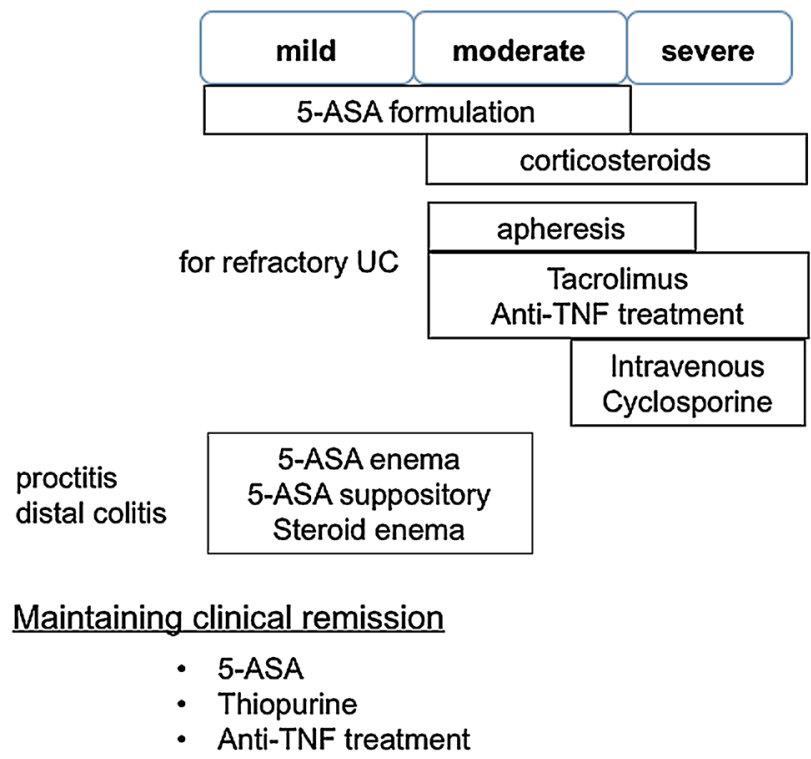

Fig. 1 Current medical treatments for ulcerative colitis

mechanism action of Tac is comparable to that of CsA, the immunosuppressive effects of Tac are greater than the effects of CsA [18]. Although Tac is useful to induce clinical and endoscopic improvements in refractory UC patients $[6,7]$, it is important to recognize the difference between the clinical trial setting and the daily clinical setting [19]. There was a delay in obtaining efficacious blood concentrations of Tac following the initiation of tacrolimus in previous clinical trials, which showed that clinical responsiveness cannot be rapidly achieved in some cases. Secondly, because measuring the concentration was frequently needed to obtain efficacious concentrations of Tac, it was difficult to treat outpatients with steroid-dependent UC with Tac because the patients had to visit the clinic 2-3 times a week at the beginning of the treatment. Recently, our prospective clinical trial indicated that clinical remission could only be obtained in $20 \%$ of 20 outpatients who were treated with Tac even when efficacious concentrations of Tac were reached within a week for most cases (Naganuma et al.; this article is written in Japanese). These results suggested that Tac should be mainly used for inpatients with moderate to severe UC. Intravenous continuous CsA is effective and used for severe fulminant UC. Although the short-term efficacy of CsA is excellent, frequent clinical recurrences and relatively higher surgical rates were observed after obtaining clinical remission in patients who used CsA [20-24]. Because Tac and anti$\mathrm{TNF} \alpha$ treatment has been available, CsA is used for fulminate UC patients only at a few institutions.

For long-term prognosis, the clinical outcome for patients with thiopurine-naive or thiopurine-intolerant UC in the Tac group was similar to the outcome for the thiopurine group because $71 \%$ of patients in the Tac group maintained clinical remission, whereas $83 \%$ of patients in the thiopurine group maintained clinical remission [25]. More recently, the patients with mucosal healing 3 months after the initiation of Tac had a better long-term clinical outcome than patients without mucosal healing [26]. In contrast to the clinical efficacy of Tac, it should be noted that the long-term adverse effects of Tac, especially renal dysfunction, have not been fully investigated.

\section{Anti-TNF $\alpha$ treatment}

The efficacy of anti-TNF $\alpha$ treatment in inducing and maintaining UC remission has been demonstrated. In Japan, two anti-TNF $\alpha$ treatments, infliximab and adalimumab, are available for UC patients. A recent metaanalysis of five trials indicated that IFX was superior to placebo in inducing the remission of moderately to severely active UC [27]. The efficacy of ADA was also evaluated in a recent randomized, double-blind, placebocontrolled trial [28]. To assess the long-term prognosis, patients who were treated with IFX were recruited to a long-term extension trial. The proportion of patients with either no disease activity or mild activity was approximately $90 \%$ for an additional 3 years [29]. In the ULTRA 2 study, the adalimumab group had a better clinical outcome than the placebo group by week 16 , and this effect was maintained up to week 52 [28]. Another recent study assessed the efficacy of adalimumab as a long-term maintenance therapy for UC, and showed that 50, 35, and $28 \%$ of patients remained well on continued treatment at 6,12 , and 24 months, respectively [30].

Inflammatory cytokines such as $\mathrm{TNF} \alpha$ play a pivotal role in inducing the apoptosis of infected cells [31]. Thus, the adverse events of greatest concern include serious infections associated with use of anti-TNF $\alpha$ agents. A recent meta-analysis of all published data from randomized controlled trials in IBD, demonstrated a twofold increase in the risk of opportunistic infections with anti-TNF $\alpha$ therapy [32]. Our recent study indicated that the use of thiopurine was an independent risk factor for opportunistic infections, whereas the use of infliximab was not associated with an increased rate of opportunistic infections [33]. Although clinicians should not hesitate to use anti-TNF $\alpha$ treatment due to increased risk of infections, screening for infections should be performed before anti-TNF treatment, and appropriate chemoprophylaxis should be given, if necessary.

When anti-TNF $\alpha$ treatment is used, it should be considered whether immunomodulators are used in combination of anti-TNF $\alpha$ treatment. The results from the UC SUCCESS trial indicated that combination therapy 
between infliximab and azathioprine was more effective than infliximab monotherapy because the corticosteroidfree remission rate by week 16 was $39.7 \%$ in combination therapy, whereas it was $22.1 \%$ in infliximab monotherapy [34]. The UC SUCCESS trial showed that more patients receiving infliximab monotherapy developed positive antiinfliximab antibodies than patients who received combination therapy [34, 35]. These results suggested that immunomodulators should be used along with infliximab. However, the physician should also recognize that some patients hate to use thiopurine due to adverse effects, such as severe bone marrow suppression and loss of hair. No study has yet assessed the usefulness of combinations of ADA and immunomodulators.

A recent study indicated that the first trough level of infliximab at week 2 was useful for predicting both shortand long-term outcomes, suggesting that dose intensification can be considered in cases of lower trough levels of infliximab [35]. The clinical practice guidelines from the Toronto UC consensus group also indicated that in patients with an inadequate response to initial anti-TNF therapy, it is important to consider dose intensification before deciding on alternative treatments [36] because patients with higher serum anti-TNF concentrations have a higher probability of induction and maintenance of complete clinical and endoscopic remission [37, 38]. Although it seems that anti-TNF $\alpha$ treatments have a better clinical outcome than calcineurin inhibitors, it should be emphasized that secondary loss of responsiveness to anti-TNFa treatments is often observed. For these patients, dose intensification may be useful to improve clinical remission. However, this efficacy was minimal in the presence of antiinfliximab antibodies, and other medical treatments should be considered in patients who are positive for the antiinfliximab antibody (Fig. 2). Unfortunately, measurement of the trough level and anti- infliximab antibody cannot be conducted in typical clinical settings in Japan.

It is unclear whether anti-TNF treatment should be discontinued after remission, and it is also unclear when
anti-TNF treatment should be discontinued. The results from a recent retrospective study [39] indicated that $48 \%$ of patients who maintained clinical remission for at least 12 months and then discontinued IFX had clinical relapses. The rate of relapse was significantly higher in patients who discontinued IFX (23.3 per 100 person-years) compared to patients who did not discontinue IFX (7.2 per 100 personyears). After discontinuation of IFX, the use of thiopurine had better outcomes compared to the use of 5-ASA alone. Among patients who had clinical relapses after discontinuation of IFX, re-induction of IFX achieved a clinical response in $77 \%$ of patients. Another study indicated that $63 \%$ of patients relapsed and $10 \%$ of patients needed a colectomy after a median follow-up of 54 months following IFX withdrawal [40]. Multivariable analysis indicated that the younger the patient was at diagnosis, the higher their platelet count was after discontinuation of IFX, and the higher counts were associated with clinical relapse. These results suggested that IFX may be discontinued after achieving clinical remission, and re-induction therapy of IFX may be effective, although caution should be taken because of the risk factors for relapse after discontinuation of IFX. Among patients who have had long-term deep remission, patients with undetectable anti-TNF drug levels can discontinue IFX [41]. A multi-center randomized control trial has been conducted to assess whether IFX can be discontinued in Japan.

\section{Treatment options include calcineurin inhibitors and anti-TNF treatment for refractory UC}

Previously, we proposed that infliximab was preferable to use for thiopurine refractory patients because the long-term prognosis of CsA may be worse than infliximab [19], whereas tacrolimus can be used in patients with severe UC who are thiopurine-naïve because thiopurine is expected to be effective in these patients after clinical remission is obtained by Tac. However, nephrotoxicity is possible, and
Fig. 2 Future treatment perspectives for loss of secondary responsiveness to anti-TNF treatments. $I F X$ infliximab, $A D A$ adalimumab, Asterisk author's opinions

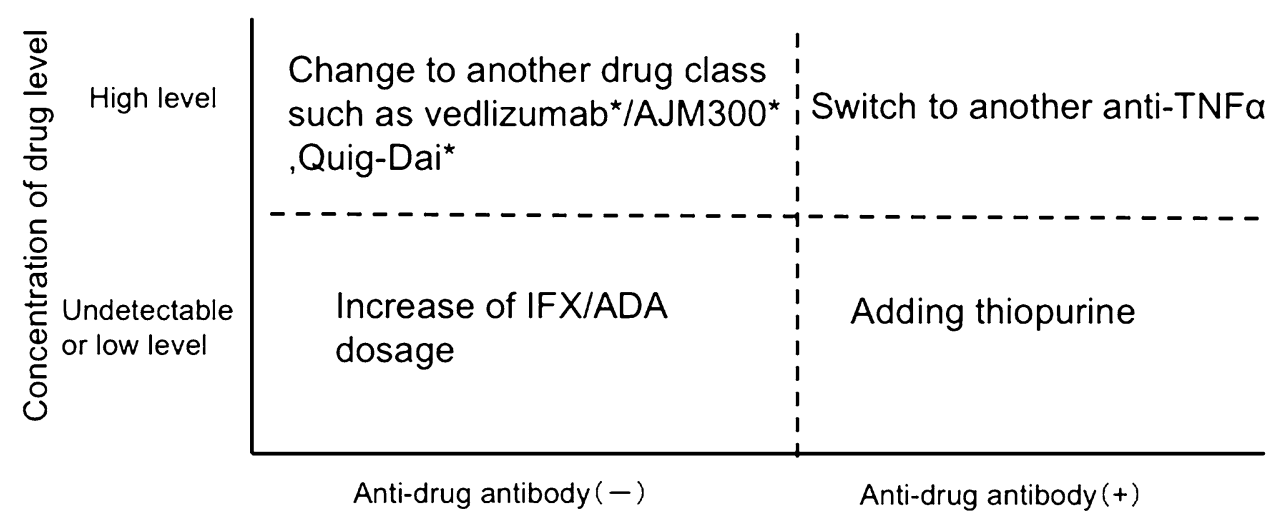


the safety of tacrolimus over a long-term period should be confirmed. Although there have been no published studies comparing the efficacy of infliximab and Tac for UC patients, the results from recent clinical trials comparing the efficacy of IFX with CsA (CYSIF trial) indicated that the efficacy of IFX and CsA was comparable in active UC patients [42]. In Japan, a clinical trial comparing the efficacy of infliximab and tacrolimus has been conducted, and the results were similar to the CYSIF trial. Because the efficacy was comparable between both treatments, it seemed that IFX was easier to use than Tac and IFX may be preferable to Tac because the frequent blood examination and adjustment of trough level is not needed in patients who are treated with IFX. On the other hand, the short halflife of Tac/CsA gives it a potential advantage over infliximab. In the event that salvage therapy fails and a colectomy is required, Tac/CsA will be cleared from the circulation far quicker than infliximab [11]. Currently, treatment options between Tac and anti-TNF treatment should be considered by physicians and the experiences of each institution [42].

\section{Upcoming treatments in the near future}

\section{Golimumab}

Golimumab is a human monoclonal IgG1 antibody for TNF- $\alpha$. Although it is not available for UC in Japan, a clinical trial was recently conducted. Golimumab is currently being developed for both anti-TNF-naïve and -resistant patients [43]. The results from the PURSUIT I study indicated that the rates of clinical response at week 6 were 51.0-54.9\% among patients who were treated with golimumab, whereas the response was $30.3 \%$ among patients given a placebo [44]. For maintaining clinical remission, golimumab was also useful, and a clinical response was maintained through week 54 in 47.0 and $49.7 \%$ of patients who were treated with 50 or $100 \mathrm{mg}$ golimumab, respectively, and in $31.2 \%$ of patients who received a placebo [45]. For maintaining remission, golimumab was given every 4 weeks. Therefore, the frequency of injection of golimumab was more than IFX (usually every 8 weeks) when golimumab was given intravenously. The PURSUIT IV study aimed to specifically compare the efficacy of intravenous and subcutaneous golimumab treatment [46]. It was confirmed that subcutaneous golimumab may be more useful because efficacy with single-dose intravenous golimumab was lower than the efficacy observed for subcutaneous golimumab. Mucosal healing was also obtained by administration of golimumab like other anti-TNF treatments. A higher serum concentration of golimumab was associated with better clinical outcomes, whereas no dose response was observed. There was no study to evaluate the efficacy of combination therapy between golimumab and thiopurine. It is not clear whether the efficacy of golimumab is better in anti-TNF-naïve patients or anti-TNFfailure patients.

\section{Vedolizumab}

Previously, the development of new medications was focused on several cytokines, including TNF- $\alpha$, IFN- $\gamma$, IL6 , Il-12/23, and IL-17. Currently, most cytokine therapies are not fundamental treatments, except for anti-TNF- $\alpha$ treatment. Over 10 years, therapies targeting leukocyte trafficking to the gut have been significantly advanced. Integrin antagonists have recently shown promising results in the induction and maintenance of remission for both $\mathrm{CD}$ and UC patients [43]. Cell-cell interactions between leukocyte and adhesion molecules on the endothelial cells of inflamed mucosa are needed to maintain the inflamed status in both CD and UC.

The leukocyte adhesion molecule inhibitor, natalizumab, blocks the $\alpha 4$ integrin subunit on lymphocytes [47]. A previous study indicated that natalizumab induced and maintained clinical remission in patients with CD [48]. However, progressive multifocal leukoencephalopathy (PML) was observed in a patient after they received natalizumab therapy for Crohn's disease. The $\alpha 4$ subunit of natalizumab is a component of gut-specific $(\alpha 4 \beta 7)$ and non-gut-specific ( $\alpha 4 \beta 1)$ integrin interactions [49]. Currently, natalizumab is available through a special restricted distribution program to mitigate the risk of PML in clinical practice.

Compared to natalizumab, vedolizumab is the humanized anti- $\alpha 4 \beta 7$ antibody and the first gut selective antiadhesion antibody used in treating IBD that minimizes offtarget treatment-related side effects. Feagan et al. demonstrated that vedolizumab had a better clinical outcome and mucosal healing [50]. Recently, the GEMINI I trial was conducted, and the results confirmed that vedolizumab was effective and safe for the induction and maintenance of moderate-to-severe UC. The response rates at week 6 were 47.1 and $25.5 \%$ among patients in the vedolizumab group and the placebo group, respectively [50]. For long-term efficacy, $41.8-44.8 \%$ of patients who continued to receive vedolizumab every 8 weeks or every 4 weeks were in clinical remission at week 52, whereas only $15.9 \%$ of patients who switched to placebo were in clinical remission at week 52 [50]. In the GEMINI I study, $44 \%$ of patients had previously received an anti-TNF treatment, and this high percentage suggested that a highly refractory group of patients were included in this study [51]. However, the odds ratio for the clinical response of vedolizumab in compared to placebo was comparable between patients 
with prior anti-TNF treatment and patients without prior anti-TNF treatment. Thus, vedolizumab may be useful for patients who are not responsive to anti-TNF treatment. Other cohort studies also indicated a relatively high clinical response (50-53\% at week 14) [52, 53] or marked decreases in the partial Mayo score at week 6 [54], which was observed although the patients had not been randomized. The adverse effects were comparable between the vedolizumab group and placebo group in most studies. No cases of progressive multifocal leukoencephalopathy have been reported in previous studies [50-54].

\section{AJM300}

AJM300 is a novel, orally active, small-molecule $\alpha 4$ integrin antagonist. The results from a recent clinical trial indicated that AJM300 was well-tolerated and more effective than placebo for inducing clinical responses $(62.7$ vs. $25.5 \%$ ), clinical remission (23.5 vs. $3.9 \%)$, and mucosal healing (58.8 vs. $29.4 \%$ ) in patients with moderately active UC [55]. Because the $\alpha 4$ integrin antagonist may cause PML, clinical development of AJM300 should be carefully conducted under a risk-management program to mitigate the potential risk for PML. As of August 2016, PML has not been observed in patients treated with AJM300. Phase III clinical trials are currently being performed in Japan.

\section{Tofacitinib}

Tofacitinib is an oral inhibitor of janus kinase (JAK) 1, 2, and 3. After the inflammatory cytokine binds to the cell surface receptor, polymerization of the receptor occurs and associated JAK molecules are activated [56]. In a double-blind, placebo-controlled, phase 2 trial, clinical remission at 8 weeks occurred in $13,33,48$, and $41 \%$ of patients who received tofacitinib at doses of $0.5,3,10$, and $15 \mathrm{mg}$, respectively, compared to $10 \%$ of patients who received a placebo. The rates of serious infection were not significantly different from placebo. However, dose-dependent increases in both low-density and high-density lipoprotein cholesterol were observed. A phase III clinical trial has been performed to confirm the safety and efficacy of tofacitinib in Japan. There has been no data to evaluate the usefulness of combination therapy with immunomodulators.

\section{Budesonide foam}

Budesonide is a high-potency corticosteroid with a low systemic effect, and it has been preferred by clinicians as an early treatment for CD rather than classic corticosteroids. Recently, we have demonstrated that twice-daily budesonide foam induced complete mucosal healing in approximately of patients with moderate distal UC. The percentages of complete mucosal healing in the twice-daily budesonide foam group were $46.4 \%$ compared to $23.6 \%$ in the once-daily group or 5.6\% in the placebo group [57]. Because complete endoscopic remission contributes to the long-term clinical outcomes in patients with UC [58], budesonide foam can be used prior to other topical therapies to achieve endoscopic remission in distal UC patients.

\section{Herbal medicine}

Traditionally, the Chinese herbal medicine Qing-Dai (also known as indigo naturalis) has been used in China to treat various inflammatory diseases. Notably, emerging evidence suggests that the crucial molecule in Qing-Dai is indole, an important group of natural aryl hydrocarbon receptor ligands that can be generated by the bacterial metabolism of tryptophan [59, 60]. These ligands induce the production of interleukin-22 from innate lymphoid cell type 3 , which results in the upregulation of the expression of tight junction molecules and antimicrobial peptides to promote mucosal healing [61, 62]. Previously, the usefulness of Qing-Dai for UC was reported [63, 64]; however, no prospective clinical trial had been conducted. Recently, we conducted a prospective study to confirm the safety and efficacy of Qing-Dai for UC [65]. Patients received QingDai twice a day (daily dose, $2 \mathrm{~g}$ ) for 8 weeks. The rates of clinical response, clinical remission, and mucosal healing were 72,33 , and $61 \%$, respectively. Adverse effects, such as mild liver dysfunction, gastrointestinal symptoms, and headache were observed. However, these were reversible events. Qing-Dai can be used for patients who are corticosteroid-resistant or corticosteroid-dependent, who do not respond to anti-TNF agents, or who cannot tolerate 5-ASA [66].

\section{Future direction and conclusions}

In the past decade, several medications have been developed for UC patients. For patients who are refractory to corticosteroids, we are able to select five treatments, including apheresis, Tac, CsA, IFX, and ADA. It is not clear how to choose among these treatments in a clinical setting. From the point view of efficacy and convenience, anti-TNF treatments may be preferable to others for refractory UC patients. However, Tac/CsA can be used for patients with more severe UC or in thiopurine naïve patients. Apheresis is needed to induce clinical remission in patients who are intolerant to corticosteroids and/or immunosuppressants because apheresis is an absolutely safe treatment compared to other medications for UC. Although several investigations have shown that dose 
Table 1 Treatment options for active UC in the near future

\begin{tabular}{|c|c|c|}
\hline & Moderate (mainly for outpatients) & Severe (mainly for inpatients) \\
\hline Steroid virgin & Corticosteroid (apheresis) & Corticosteroid \\
\hline Steroid naïve & $\begin{array}{l}\text { Corticosteroid (AZA is given after inducing remission) } \\
\text { Apheresis } \\
{\text { AJM } 300^{\mathrm{a}}}^{\text {Vedolizumab }^{\mathrm{a}}} \\
\text { Tofacitinib }^{\mathrm{a}} \\
\text { Infliximab, adalimumab }\end{array}$ & $\begin{array}{l}\text { Corticosteroid (AZA is given after inducing remission) } \\
\text { Tacrolimus } \\
\text { Infliximab } \\
\text { Vedolizumab }^{\mathrm{a}}\end{array}$ \\
\hline Steroid refractory & $\begin{array}{l}\text { Apheresis } \\
{\text { AJM } 300^{\mathrm{a}}}^{\mathrm{a}} \\
\text { Vedolizumab }^{\mathrm{a}} \\
\text { Infliximab, adalimumab }\end{array}$ & $\begin{array}{l}\text { Tacrolimus } \\
\text { Infliximab } \\
\text { Cyclosporine (for fulminate case) }\end{array}$ \\
\hline Steroid dependent & $\begin{array}{l}\text { Infliximab, adalimumab } \\
\text { Tacrolimus } \\
{\text { AJM } 300^{\mathrm{a}}}^{\text {Vedolizumab }^{\mathrm{a}}} \\
\text { Tofacitinib }^{\mathrm{a}} \\
\text { Qing-Dai }^{\mathrm{a}}\end{array}$ & \\
\hline
\end{tabular}

Steroid virgin patients who never previously received systemic corticosteroids

Steroid naïve patients who did not receive systemic corticosteroids in cases of clinical recurrence

a Author's opinions

optimization is useful to achieve a clinical response in patients with anti-TNF treatment failure or who lost secondary responsiveness to anti-TNF treatment, we should consider the cost-effectiveness of optimizing anti-TNF treatment. Furthermore, the measurement of the trough concentrations and anti-IFX/ADA antibodies is possible in only a few countries. Intensive research for the development of other cost-effective biomarkers to predict the presence of anti-IFX/ADA antibodies should be conducted. AJM300 and to facitinib will be mainly used in moderate UC outpatients because these treatments are administered orally. Vedolizumab may be the preferred treatment for anti-TNF naïve patients, but it seems to also be useful for patients who were previously treated with anti-TNF treatments. In the near future, physicians will able to use many different treatments for UC patients as Table 1 indicated. However, we should not forget 5-ASA and corticosteroids as the fundamental treatments for UC patients.

\section{Compliance with ethical standards}

Conflict of interest: Within the last 2 years, Takanori Kanai has received scholarship funds for the research from Asaki Kasei Medical Co. Ltd, Astellas Pharm Inc, JIMRO Co. Ltd., Eisai Pharmaceutical Co. Ltd., Pfizer Japan Inc, Takeda Pharmaceutical Co. Ltd., Tanabe Mitsubishi Pharmaceutical Co. Ltd., Zeria Pharmaceutical Co. Ltd. All other authors declare that they have no conflict of interest.

Human rights: This is the review article and does not include any data about human subjects.
Informed consent: Because this manuscript is review article. Thus, informed contents could not obtained from patients.

\section{References}

1. Yun L, Hanauer S. Selecting appropriate anti-TNF agents in inflammatory bowel disease. Expert Rev Gastroenterol Hepatol. 2009;3:235-48.

2. Schroeder KW, Tremaine WJ, Ilstrup DM. Coated oral 5-aminosalicylic acid therapy for mildly to moderately active ulcerative colitis. A randomized study. N Engl J Med. 1987;317: $1625-9$.

3. Ford AC, Bernstein CN, Khan KJ, Abreu MT, Marshall JK, Talley NJ, et al. Glucocorticosteroid therapy in inflammatory bowel disease: systematic review and meta-analysis. Am J Gastroenterol. 2011;106:590-9.

4. Gisbert JP, Linares PM, McNicholl AG, Maté J, Gomollón F. Meta-analysis: the efficacy of azathioprine and mercaptopurine in ulcerative colitis. Aliment Pharmacol Ther. 2009;30:126-37.

5. Khan KJ, Dubinsky MC, Ford AC, Ullman TA, Talley NJ, Moayyedi P. Efficacy of immunosuppressive therapy for inflammatory bowel disease: a systematic review and metaanalysis. Am J Gastroenterol. 2011;106:630-42.

6. Lichtiger S, Present DH, Kornbluth A, Gelernt I, Bauer J, Galler $\mathrm{G}$, et al. Cyclosporine in severe ulcerative colitis refractory to steroid therapy. N Engl J Med. 1994;330:1841-5.

7. Ogata H, Matsui T, Nakamura M, Iida M, Takazoe M, Suzuki Y, et al. A randomised dose finding study of oral tacrolimus (FK506) therapy in refractory ulcerative colitis. Gut. 2006;55: $1255-62$.

8. Ogata H, Kato J, Hirai F, Hida N, Matsui T, Matsumoto T, Koyanagi K, Hibi T. Double-blind, placebo-controlled trial of oral tacrolimus (FK506) in the management of hospitalized 
patients with steroid-refractory ulcerative colitis. Inflamm Bowel Dis. 2012;18:803-8.

9. Rutgeerts P, Sandborn WJ, Feagan BG, Reinisch W, Olson A, Johanns J, et al. Infliximab for induction and maintenance therapy for ulcerative colitis. N Engl J Med. 2005;353:2462-76.

10. Reinisch W, Sandborn WJ, Hommes DW, D'Haens G, Hanauer $\mathrm{S}$, Schreiber S, et al. Adalimumab for induction of clinical remission in moderately to severely active ulcerative colitis: results of a randomised controlled trial. Gut. 2011;60:780-7.

11. Dignass A, Lindsay JO, Sturm A, Windsor A, Colombel JF, Allez $\mathrm{M}$, et al. Second European evidence-based consensus on the diagnosis and management of ulcerative colitis part 2: current management. J Crohns Colitis. 2012;6:991-1030.

12. Naganuma M, Sakuraba A, Hibi T. Ulcerative colitis: prevention of relapse. Expert Rev Gastroenterol Hepatol. 2013;7:341-51.

13. Naganuma M, Funakoshi S, Sakuraba A, Takagi H, Inoue N, Ogata $\mathrm{H}$, et al. Granulocytopheresis is useful as an alterative therapy for steroid refractory and dependent ulcerative colitis. Inflamm Bowel Dis. 2004;10:251-7.

14. Sakuraba A, Sato T, Naganuma M, Morohoshi Y, Matsuoka K, Inoue $\mathrm{N}$, et al. A pilot open-labeled prospective randomized study between weekly and intensive treatment of granulocyte and monocyte adsorption apheresis for active ulcerative colitis. J Gastroenterol. 2008;43:51-6.

15. Sawada K, Kusugami K, Suzuki Y, Bamba T, Munakata A, Hibi $\mathrm{T}$, et al. Leukocytapheresis in ulcerative colitis: results of a multicenter double-blind prospective case-control study with sham apheresis as placebo treatment. Am J Gastroenterol. 2005; 100:1362-9.

16. Sawada K, Muto T, Shimoyama T, Satomi M, Sawada T, Nagawa $\mathrm{H}$, et al. Multicenter randomized controlled trial for the treatment of ulcerative colitis with a leukocytapheresis column. Curr Pharm Des. 2003;9:307-21.

17. Sands BE, Sandborn WJ, Feagan B, Löfberg R, Hibi T, Wang T, et al. A randomized, double-blind, sham-controlled study of granulocyte/monocyte apheresis for active ulcerative colitis. Gastroenterology. 2008;135:400-9.

18. Järnerot G, Hertervig E, Friis-liby I, Blomquist L, Karlén P, Grännö C, et al. Infliximab as rescue therapy in severe to moderately severe ulcerative colitis: a randomized placebo-controlled study. Gastroenterology. 2005;128:1805-11.

19. Naganuma M, Fujii T, Watanabe M. The use of traditional and newer calcineurin inhibitors in inflammatory bowel disease. J Gastroenterol. 2011;46:129-37.

20. Moskovitz D, Van Assche G, Maenhout B, Arts J, Ferrante M, Vermeire S, et al. Incidence of colectomy during long term follow up after cyclosporin-induced remission of severe ulcerative colitis. Clin Gastroenterol Hepatol. 2006;4:760-5.

21. Campbell S, Travis S, Jewell D. Ciclosporin use in acute ulcerative colitis: a long-term experience. Eur J Gastroenterol Hepatol. 2005; 17:79-84.

22. Arts J, D'Haens G, Zeegers M, Van Assche G, Hiele M, D'Hoore A, et al. Long-term outcome of treatment with intravenous cyclosporin in patients with severe ulcerative colitis. Inflamm Bowel Dis. 2004;10:73-8.

23. Message L, Bourreille A, Laharie D, Quinton A, Galmiche JP, Lamouliatte $\mathrm{H}$, et al. Efficacy of intravenous cyclosporin in moderately severe ulcerative colitis refractory to steroids. Gastroenterol Clin Biol. 2005;29:231-5.

24. Kobayashi T, Naganuma M, Okamoto S, Hisamatsu T, Inoue N, Ichikawa $\mathrm{H}$, et al. Rapid endoscopic improvement is necessary for 1-year avoidance of colectomy but not for the long-term prognosis in patients with ulcerative colitis treated with cyclosporine A teatment for ulcerative coltis. J Gastroenterol. 2010;45:1129-37.
25. Yamamoto S, Nakase H, Matsuura M, Masuda S, Inui K, Chiba T. Tacrolimus therapy as an alternative to thiopurines for maintaining remission in patients with refractory ulcerative colitis. J Clin Gastroenterol. 2011;45:526-30.

26. Miyoshi J, Matsuoka K, Inoue N, Hisamatsu T, Ichikawa R, Yajima T, et al. Mucosal healing with oral tacrolimus is associated with favorable medium- and long-term prognosis in steroidrefractory/dependent ulcerative colitis patients. J Crohns Colitis. 2013;7:e609-14.

27. Ford AC, Sandborn WJ, Khan KJ, Hanauer SB, Talley NJ, Moayyedi P. Efficacy of biological therapies in inflammatory bowel disease: systematic review and meta-analysis. Am J Gastroenterol. 2011;106:644-59.

28. Sandborn WJ, van Assche G, Reinisch W, Colombel JF, D'Haens $\mathrm{G}$, Wolf DC, et al. Adalimumab induces and maintains clinical remission in patients with moderate-to-severe ulcerative colitis. Gastroenterology. 2012;142:257-65.

29. Reinisch W, Sandborn WJ, Rutgeerts P, Feagan BG, Rachmilewitz D, Hanauer SB. Long-term infliximab maintenance therapy for ulcerative colitis: the ACT-1 and -2 extension studies. Inflamm Bowel Dis. 2012;18:201-11.

30. McDermott E, Murphy S, Keegan D, O’Donoghue D, Mulcahy H, Doherty G. Efficacy of adalimumab as a long term maintenance therapy in ulcerative colitis. J Crohns Colitis. 2013;7:150-3.

31. Kollas G, Kontoyiannis D. Role of TNF/TNFR in autoimmunity: specific TNF receptor blockade may be advantageous to anti-TNF treatments. Cytokine Growth Factor Rev. 2002;13:315-21.

32. Ford AC, Peyrin-Biroulet L. Opportunistic infections with antitumor necrosis factor- $\alpha$ therapy in inflammatory bowel disease: meta-analysis of randomized controlled trials. Am J Gastroenterol. 2013;108:1268-76.

33. Naganuma M, Kunisaki R, Yoshimura N, Takeuchi Y, Watanabe M. A prospective analysis of the incidence of and risk factors for opportunistic infections in patients with inflammatory bowel disease. J Gastroenterol. 2013;48:595-600.

34. Panaccione R, Ghosh S, Middleton S, Marquez J, Scott B, Flint L, et al. Combination therapy with infliximab and azathioprine is superior to monotherapy with either agent in ulcerative colitis. Gastroenterology. 2014;146:392-400.

35. Kobayashi T, Suzuki Y, Motoya S, Hirai F, Ogata H, Ito H, et al. First trough level of infliximab at week 2 predicts future outcomes of induction therapy in ulcerative colitis-results from a multicenter prospective randomized controlled trial and its post hoc analysis. J Gastroenterol. 2016;51:241-51.

36. Bressler B, Marshall JK, Bernstein CN, Bitton A, Jones J, Leontiadis GI, et al. Clinical practice guidelines for the medical management of nonhospitalized ulcerative colitis: the Toronto consensus. Gastroenterology. 2015;148:1035-58.

37. Roblin X, Marotte H, Rinaudo M, Del Tedesco E, Moreau A, Phelip JM, et al. Association between pharmacokinetics of adalimumab and mucosal healing in patients with inflammatory bowel diseases. Clin Gastroenterol Hepatol. 2014;12:80-4.

38. Hibi T, Sakuraba A, Watanabe M, Motoya S, Ito H, Motegi $\mathrm{K}$, et al. Retrieval of serum infliximab level by shortening the maintenance infusion interval is correlated with clinical efficacy in Crohn's disease. Inflamm Bowel Dis. 2012;18:1480-7.

39. Fiorino G, Cortes PN, Ellul P, Felice C, Karatzas P, Silva M, et al. Discontinuation of infliximab in patients with ulcerative colitis is associated with increased risk of relapse: a multinational retrospective cohort study. Clin Gastroenterol Hepatol. 2016; 14(10):1426-32.

40. Le Roy F, Siproudhis L, Bretagne JF, Bouguen G. Long-term infliximab therapy is needed for sustained steroid-free remission in patients with ulcerative colitis. Dig Liver Dis. 2016;48:208-9. 
41. Ben-Horin S, Chowers Y, Ungar B, Kopylov U, Loebstein R, Weiss $\mathrm{B}$, et al. Undetectable anti-TNF drug levels in patients with longterm remission predict successful drug withdrawal. Aliment Pharmacol Ther. 2015;42:356-64.

42. Laharie D, Bourreille A, Branche J, Allez M, Bouhnik Y, Filippi J, et al. Ciclosporin versus infliximab in patients with severe ulcerative colitis refractory to intravenous steroids: a parallel, open-label randomised controlled trial. Lancet. 2012;380:1909-15.

43. Ungar B, Kopylov U. Advances in the development of new biologics in inflammatory bowel disease. Ann Gastroenterol. 2016;29:243.

44. Sandborn WJ, Feagan BG, Marano C, Zhang H, Strauss R, Johanns J, et al. Subcutaneous golimumab induces clinical response and remission in patients with moderate-to-severe ulcerative colitis. Gastroenterology. 2014;146:85-95.

45. Sandborn WJ, Feagan BG, Marano C, Zhang H, Strauss R, Johanns J, et al. Subcutaneous golimumab maintains clinical response in patients with moderate-to-severe ulcerative colitis. Gastroenterology. 2014;146:96-109.

46. Rutgeerts P, Feagan BG, Marano C, Padgett L, Strauss R, Johanns J, et al. Randomised clinical trial: a placebo-controlled study of intravenous golimumab induction therapy for ulcerative colitis. Aliment Pharmacol Ther. 2015;42:504-14.

47. Keeley KA, Rivey MP, Allington DR. Natalizumab for the treatment of multiple sclerosis and Crohn's disease. Ann Pharmacother. 2005;39:1833-43.

48. Sandborn WJ, Colombel JF, Enns R, Feagan BG, Hanauer SB, Lawrance IC, et al. Natalizumab induction and maintenance therapy for Crohn's disease. N Engl J Med. 2005;353:1912-25.

49. Levesque BG, Ghosh S. Targeting integrins and safety in an emerging class of targeted oral therapies: are we prepared for rational and precision Choices? Gastroenterology. 2015;149:1669-72.

50. Feagan BG, Rutgeerts P, Sands BE, Hanauer S, Colombel JF, Sandborn WJ, et al. Vedolizumab as induction and maintenance therapy for ulcerative colitis. N Engl J Med. 2013;369:699-710.

51. Sands BE. New drugs on the horizon for IBD. Dig Dis. 2014;32(Suppl 1):74-81.

52. Shelton E, Allegretti JR, Stevens B, Lucci M, Khalili H, Nguyen $\mathrm{DD}$, et al. Efficacy of vedolizumab as induction therapy in refractory IBD patients: a multicenter cohort. Inflamm Bowel Dis. 2015;21:2879-85.

53. Amiot A, Grimaud JC, Peyrin-Biroulet L, Filippi J, Pariente B, Roblin X, et al. Effectiveness and safety of vedolizumab induction therapy for patients with inflammatory bowel disease. Clin Gastroenterol Hepatol. 2016. doi:10.1016/j.cgh.2016.02.016

54. Vivio EE, Kanuri N, Gilbertsen JJ, Monroe K, Dey N, Chen $\mathrm{CH}$, et al. Vedolizumab effectiveness and safety over the first year of use in an IBD clinical practice. J Crohn's Colitis. 2016;10:402-9.

55. Yoshimura N, Watanabe M, Motoya S, Tominaga K, Matsuoka K, Iwakiri R, et al. Safety and efficacy of AJM300, an oral antagonist of $\alpha 4$ integrin, in induction therapy for patients with active ulcerative colitis. Gastroenterology. 2015;149:1775-83.

56. Sandborn WJ, Ghosh S, Panes J, Vranic I, Su C, Rousell S, et al. Tofacitinib, an oral Janus kinase inhibitor, in active ulcerative colitis. N Engl J Med. 2012;367:616-24.

57. Naganuma M, Aoyama N, Suzuki Y, Nishino H, Kobayashi K, Hirai $\mathrm{F}$, et al. Twice-daily budesonide $2 \mathrm{mg}$ foam induces complete mucosal healing in patients with distal ulcerative colitis. J Crohn's Colitis. 2016;10:828-36.

58. Arai M, Naganuma M, Sugimoto S, Kiyohara H, Ono K, Mori K, et al. The ulcerative colitis endoscopic index of severity (UCEIS) is useful to predict medium to long-term prognosis in ulcerative colitis patients with clinical remission. J Crohn Colitis. 2016.

59. Stockinger B, Di Meglio P, Gialitakis M, et al. The aryl hydrocarbon receptor: multitasking in the immune system. Annu Rev Immunol. 2014;32:403-32.

60. Zelante T, Iannitti RG, Cunha C, De Luca A, Giovannini G, Pieraccini $\mathrm{G}$, et al. Tryptophan catabolites from microbiota engage aryl hydrocarbon receptor and balance mucosal reactivity via interleukin-22. Immunity. 2013;39:372-85.

61. Qiu J, Guo X, Chen ZM, He L, Sonnenberg GF, Artis D, et al. Group 3 innate lymphoid cells inhibit T-cell-mediated intestinal inflammation through aryl hydrocarbon receptor signaling and regulation of microflora. Immunity. 2013;39:386-99.

62. Liu JZ, Pezeshki M, Raffatellu M. Th17 cytokines and hostpathogen interactions at the mucosa: dichotomies of help and harm. Cytokine. 2009;48:156-60.

63. Yuan G, Ke Q, Su X, Yang J, Xu X. Qing Dai, a traditional Chinese medicine for the treatment of chronic hemorrhagic radiation proctitis. Chin Ger J Clin Oncol. 2009;8:114-6.

64. Suzuki H, Kaneko T, Mizokami Y, Narasaka T, Endo S, Matsui $\mathrm{H}$, et al. Therapeutic efficacy of the Qing Dai in patients with intractable ulcerative colitis. World J Gastroenterol. 2013;19: 2718-22.

65. Sugimoto S, Naganuma M, Kiyohara H, Arai M, Ono K, Mori K, et al. Clinical efficacy and safety of oral Qing-Dai in patients with ulcerative colitis: a single-center open-label prospective study. Digestion. 2016;93:193-201.

66. Sugimoto S, Naganuma M, Kanai T. Indole compounds may be promising medicines for ulcerative colitis. J Gastroenterol. 2016;51:853-61. 